\title{
STUDI KRITIS KONSEP SANAD KITAB NAHJ AL-BALAGHAH SEBAGAI UPAYA MEMBANGUN BUDAYA TABAYYUN DALAM KEILMUAN ISLAM
}

\author{
Agus Hasan Bashori ${ }^{1}$ dan Vlil Amri Syafri ${ }^{2}$ \\ ${ }^{1}$ Ma'had Ali al-Aimmah; ${ }^{2}$ Pascasarjana UIKA; \\ Email: abu_hamzah@msn.com
}

\section{Abstract}

Tabayyun or tatsabbut or tahaqquq (verification) and taakkud (confirmation) of the news are important in order to prevent doing something wrong, injustice and regret. While in science and religion, tatsabbut is more important because the consequences could be dangerous. Therefore, Muslims as ummatan wasatan have been given by God the privilege to be the people whose religion and science have sanad. At the time of the salaf, tatsabbut with sanad was common through talaqqi and historical verification. In order to revive the culture of this tatsabbut, it needs a critical study on the sanad concept in a famous and wide spread of Nahj al-Balaghah book. The research questions are, how is the concept of sanad in the book Nahj al-Balagha? Does Nahj al-Balagha contain the belief of tasyayyu 'Ghali (Rafidhah) and bara'ah (seperating themselves) from the prophet's companions? This research used qualitative method, through a literature review and a descriptive documentary analysis. The finding shows that the book Nahj al-Balagha doesn not have sanad and its concept. Furthermore its content rejects and hates the companions of the Prophet and his wives.

Tabayyun atau tatsabbut atau tahaqquq (verifikasi) dan taakkud (konfirmasi) dalam berita adalah penting agar kita tidak berbuat salah, zalim dan menyesal. Sedangkan dalam ilmu dan agama tatsabbut itu lebih penting lagi sebab akibatnya bisa lebih fatal. Oleh karena itu umat Islam yang dijadikan oleh Allah sebagai

el Harakah Jurnal Budaya Islam Vol.18 No.2 Tahun 2016 
ummatan wasatanan diberi keistimewaan sebagai umat yang agama dan ilmunya ber-sanad. Di zaman salaf, tatsabbut dengan sanad sudah membudaya dalam talaqqi dan riwayat. Maka untuk menghidupkan kembali budaya tastabbut ini peneliti memandang perlu melakukan studi kritis terhadap konsep sanad yang ada dalam kitab Nahj al-Balaghah yang kesohor dan tersebar luas itu. Maka rumusan masalahnya adalah bagaimana konsep sanad dalam kitab Nahj al-Balaghah? Apakah Nahj Balaghah berisi akidah tasyayyu' ghali (Rafidhah) dan bara'ah (berlepas diri) dari para sahabat Nabi? Penelitian ini menggunakan metode kualitatif, melalui kajian literatur atau kepustakaan dan analisis dokumen secara deskriptif. Hasilnya, kita mendapatkan bahwa kitab Nahj alBalaghah tidak memiliki sanad dan tidak memiliki konsep sanad, dan isinya menolak dan membenci para sahabat Nabi, dan istri-istrinya.

Keywords: concept; culture; Nahj al-Balaghah; sanad; tabayyun.

\section{Pendahuluan}

Ilmu mempunyai peranan yang sangat penting dalam membangun masyarakat atau bangsa. Bangsa yang mempunyai tradisi keilmuan yang kuat akan mempunyai pengaruh yang besar kepada bangsa lain yang jauh lebih besar jumlah rakyatnya dan lebih kuat bala tentaranya. Sebagai contoh, bangsa Yunani dahulu adalah sebuah bangsa yang gemar akan ilmu pengetahuan. Karena itu pengaruh hasil keilmuan bangsa Yunani begitu berpengaruh besar terhadap bangsa-bangsa lain, salah satunya terhadap bangsa Romawi (Nasir, 2012). Lebih dari itu, bangsa Arab Jahiliyah pun akhirnya menjadi pemimpin dunia karena ilmu yang dibawa oleh Nabi Muhammad saw. Dengan ilmu Islam ini bangsa Arab yang asalnya buta huruf dan miskin dapat mengalahkan Persia dan Romawi dalam waktu singkat.

Semua ilmu yang bermanfaat bagi manusia dan tidak bertentangan dengan petunjuk yang dibawa oleh Nabi Muhammad saw. adalah termasuk bagian dari ilmu Islam. Oleh karenanya, ilmu yang ada digunakan untuk mengenal Allah swt., mengimani-Nya, mencintai-Nya, dan mentaati-Nya agar mendapatkan kebahagiaan di dunia dan di akhirat. Ilmu Islam yang bersifat naqli ini disampaikan melalui sanad yang merupakan keistimewaan dan ciri khas umat Nabi Muhammad saw. Sanad ilmu Islam bermula dari Allah yang kemudian dibawa Jibril kepada Nabi Muhammad saw. yang selanjutnya diwariskan kepada sahabatnya untuk disampaikan kepada manusia sesudah mereka. Cara ini tidak digunakan umat-umat terdahulu dalam mempelajari agama mereka, karena itu banyak terjadi tahrif (penyimpangan) dalam kitab- 
kitab mereka (Taimiyyah, 1999: 3/26-27, 6/349; Hindi, t.t.: 1/111, 2/425-625, $650,617)$

Secara bahasa, sanad adalah mu'tamad (sandaran) (Manzhur, t.t.). Sedangkan kata kerja صعدورقى atau صنَ artinya (naik) (Zamakhsyari: t.t.: 300). Secara istilah menurut ahli Hadis, sanad adalah: "Jalan yang menyampaikan (mengantarkan) kepada matan" (Anshari, t.t.: 1/16). Yang dimaksud dengan jalan adalah: "Silsilah (rentetan) para perawi yang mentransmisikan hadis secara berantai, dari seseorang ke yang lain, dari sumber yang pertama, yaitu Rasulullah saw. atau orang yang lebih rendah di bawahnya, yaitu sahabat atau tabi'in." (Qari, t.t.: 18-19).

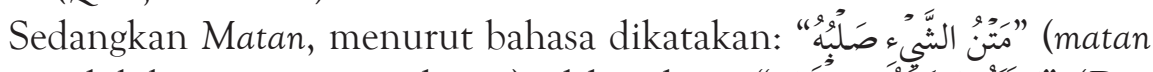

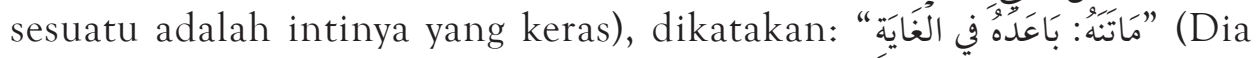
membawanya jauh ke dalam tujuan) (Manzhur, t,t.). Sécara î́tilah, Badruddin ibn Jama'ah berkata: "Matan adalah ucapan (berita) yang dicapai oleh akhir sanad” (Jama'ah, t.t.).

Kata Isnad secara bahasa adalah kata benda bentukan dari asnada yang artinya menyandarkan. Secara istilah diterangkan oleh Ibn Hajar al-Asqalani mengatakan: "Isnad adalah hikayat (menceritakan) jalannya matan" (Asqalani, t.t.). Makna hikayat adalah memberitahu jalur transmisinya sampai sumbernya yang pertama.

Para ahli hadis sangat perhatian dengan Isnad karena ia merupakan jalan untuk mengetahui hadis Nabi Muhammad saw. yang merupakan sumber Islam kedua setelah al-Quran. Dengan menelusuri para pembawa berita ini akan diketahui mana berita yang sahih dan mana yang tidak sahih. Para ulama mengatakan bahwa Isnad adalah separuh ilmu hadis, sebab hadis terdiri dari bagian Isnad dan matan (Fayyadh, 2007: 133).

Allah swt. berfirman:

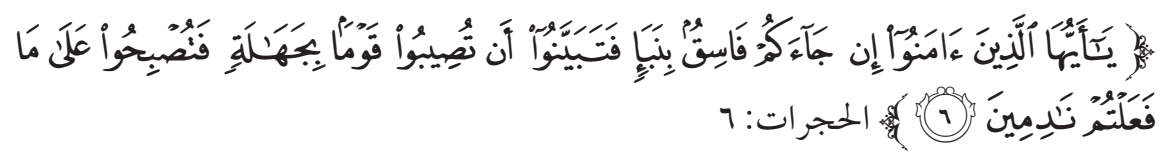

Wahai orang-orang yang beriman, jika ada orang fasik datang kepadamu dengan membawa berita, maka kamu harus melakukan tabayyun (meneliti tentang kebenaran tidaknya berita tersebut), agar kamu tidak menimpakan musibah di suatu kaum tanpa mengetahui keadaannya, akibatnya kamu akan menyesali apa yang kamu lakukan. (Q.S: al-Hujurat: 6).

Rasulullah saw. bersabda:

el Harakah Jurnal Budaya Islam Vol.18 No.2 Tahun 2016 
"Barangsiapa berdusta atasku dengan sengaja maka silahkan mengambil tempat duduknya dari neraka" (Bukhari, t.t.: 1/33 no. 107; Naisaburi, t.t.: 1/10, 4/2298 no. 3004; Rifa'i, t.t.: 1/9). "Barangsiapa menceritakan dariku satu hadis yang diduga dusta maka dia salah seorang dari dua orang yang berdusta (Naisaburi, t.t.: 1/8). Sementara Nabi saw. memberi kabar surga bagi yang menyampaikan hadis dengan benar, hafal sesuai dengan apa yang dia dengar (Sijistani, t.t.: 3/322 no. 3660; Turmudzi, 1975: 5/34).

Hadis-hadis Nabi Muhammad saw. di atas memperlihatkan bahwa konsep sanad dalam Islam sangat penting karena merupakan salah satu tradisi dalam keilmuan Islam. Konsep ini sesuai dengan semangat metode cek dan ricek dalam konsep keilmuan di dunia Barat. Penyusuran terperinci secara ilmiah menjadikan sebuah karya ilmiah menjadi kuat dan dipercaya sehingga hasilnya dapat dimanfaatkan untuk kepentingan ilmu pengetahuan.

Terkait dengan hal itu, peneliti merasa tertarik meneliti kitab Nahj alBalaghah, salah satu kitab sastra kesohor yang ditulis oleh Syarif Radhi yaitu Abu al-Hasan Muhammad bin Abi Ahmad ath-Thahir al-Husain bin Musa al-Abrasi bin Muhammad al-A'raj bin Musa (Abu Sabhah) bin Ibrahim alAshghar bin Imam Musa bin Imam Ja'far ash-Shadiq, salah satu ulama besar Syiah yang juga seorang penyair terkemuka pada zamannya. Dalam kitab ini, Syarif Radhi menceritakan bahwa Imam Ali adalah seorang penyair dan ahli sastra yang paling produktif tempat kelahiran balaghah (Hadid, 1965: 45).

Orang Syiah meyakini bahwa kitab Nahj al-Balaghah merupakan kitab yang paling lengkap dalam menghimpun apa yang dianggap mereka sebagai bagian dari ilmu yang diwariskan oleh Imam Ali, sekaligus kitab yang paling suci setelah al-Quran. Hal ini diungkapkan oleh Imam Khumaini dalam wasiat politiknya yang diklaim sebagai "Ilahiyyah". (Khumaini, t.t.; Anonim (Kedubes Iran di Jakarta), t.t.: 79).

Kitab Nahj al-Balaghah sudah banyak diterbitkan dalam berbagai macam bahasa, tak terkecuali dalam bahasa Indonesia. Di Indonesia sendiri kitab ini telah memiliki terjemahan dengan berbagai macam versi dari penerbit Mizan, YAPI Bangil, Lentera, al-Huda Jakarta, Cahaya Bogor, dan Trisula Adisakti Jakarta. Dari keenam penerbit ini, ada dua yang buku-buku terbitannya menjadi referensi kurikulum PAI di Sekolah Dasar. Salah satunya adalah penerbit Mizan dan kelompoknya yang mendominasi KTSP 2006 dan Kurikulum 2013. (Bashori, 2016: 7-8)

Penulis telah melakukan kajian pustaka meliputi empat karya ilmiah tentang Nahj al-Balaghah (1 skripsi, 11 tesis, dan 3 disertasi) yang berasal dari 
Irak, Palestina, Malaysia, dan Indonesia terkait dengan penelitian yang bersifat linguistik dan semiotik. Hasilnya memperlihatkan bahwa semua peneliti mempercayai bahwa Nahj al-Balaghah sahih dari Imam Ali dan bersepakat tentang keindahannya. (Bashori, 2016: 14-20).

Hanya saja, dari penelitian-penelitian tersebut tidak ada satu pun yang mengkritisi kandungan kitab Nahj al-Balaghah secara Syar'i, padahal Nabi Muhammad saw. pernah mengomentari seorang khatib yang berkata benar secara bahasa namun salah secara adab syar'i, "Seburuk-buruk penceramah adalah kamu, katakan: Barangsiapa bermaksiat kepada Allah dan Rasul-Nya maka dia telah sesat." Kritikan ini, Rasulullah sampaikan karena khatib itu berkata: "Barangsiapa mentaati Allah dan Rasul-Nya maka dia telah lurus, dan barangsiapa bermaksiat kepada keduanya maka telah sesat.” (Naisaburi, t.t.: 2/870)

Oleh karena itu, penulis tidak sependapat jika kitab Nahj al-Balaghah hanya diteliti pada masalah keindahan sastra dan keluasan cakupannya, tanpa diukur dengan al-Quran dan as-Sunnah. Perlu penelitian yang mendalam pada sisi lain, misalnya pada hal akidah, syariat, dan lainnya. Maka, penelitian ini mencoba melihat bagaimana konsep sanad dalam kitab Nahj al-Balaghah dan meneliti kandungan isi kitab tersebut dalam hubungannya dengan tradisi keilmuan Islam. Hal ini dimaksudkan agar para pembaca kitab Nahj al-Balaghah tidak hanya terfokus pada gaya bahasa dan sastra yang digunakan, namun juga dapat melihat lebih jernih kandungan dan isi kitab tersebut sesuai dengan ukuran al-Quran dan as-Sunnah.

\section{Metode Penelitian}

Penelitian ini menggunakan metode kualitatif melalui kajian literatur atau kepustakaan dan menganalisanya secara deskriptif. Data-data utama yang digunakan bersumber dari kitab Nahj al-Balaghah kemudian kita lengkapi dengan kitab Khashaish al-Aimmah yang juga karya Syarif Radhi, bahkan bisa dikatakan kitab Khashaish al-Aimmah merupakan bab pertama bagi kitab Nahj al-Balaghah. Oleh karena itu kedua kitab ini merupakan satu kesatuan yang tidak terpisahkan. Sedangkan beberapa karya ulama lain sebagai syarah (penjelasan) atas karya-karya Syarif Radhi khususnya tentang konsepsi ilmu, juga kitab-kitab, makalah, artikel, dan hasil penelitian yang berkenaan dengan tokoh Syarif Radhi maupun kitabnya Nahj al-Balaghah, baik yang pro maupun yang kontra.

Pendekatan yang digunakan dalam penelitian ini adalah pendekatan historis dan fenomenologis. Peneliti mengumpulkan data dengan merujuk kepada 
fakta-fakta yang berbentuk sejarah atau kajian-kajian lampau berkenaan dengan Nahj al-Balaghah. Hal ini untuk meninjau bagaimana sejarah mempengaruhi penulis Nahj al-Balaghah untuk menuangkan ide-idenya dalam kitab ini.

Dalam menganalisis data-data, penelitian ini menggunakan teknik content analysis dan analisis deskriptif kualitatif. Teknik analisis isi digunakan untuk mengolah data konsep ilmu dalam kitab Nahj al-Balaghah, sehingga diperoleh kesimpulan dari berbagai pemikiran yang diteliti dan kemungkinan implikasi serta konsekuensinya. Dengan demikian, akan mudah ditarik benang merah corak dan aliran pemikiran penulis kitab Nahj al-Balaghah, khususnya dalam masalah ilmu.

Ada beberapa langkah penelitian. Pertama, mengumpulkan sumber utama, yaitu Kitab Nahj al-Balaghah kemudian kitab Khashaish al-Aimmah, yang terkait konsepsi ilmu, buku-buku sejarah kehidupan Syarif Radhi, dan sumber pelengkap lain yang berupa kitab-kitab syarah (penjelasan) Ibnu Abi al-Hadid, terjemahannya dan kitab-kitab lain yang berkaitan. Kedua, mengklasifikasikan data berdasarkan teori konsep ilmu, dan mendeskripsikan. Ketiga, mendeskripsikan konsep ilmu Ahlussunnah berdasarkan al-Quran dan as-Sunnah yang diwakili oleh Imam Syafi'i dan al-Hafidz bin Abd al-Barr sebagai alat ukur bagi konsep ilmu Nahj al-Balaghah. Keempat, melakukan kritik terhadap konsep ilmu Nahj al-Balaghah dan menghubungkannya dengan pokok pembahasan. Kritik yang dimaksud adalah kritik ahli Hadis tentang sanad dan matannya. Kelima, menyimpulkan hasil-hasil analisis tersebut sehingga terjawab permasalahan-permasalahan yang ada.

\section{Pembahasan}

\section{Tentang Kitab Nahj al-Balaghah}

Kitab Nahj al-Balaghah ditulis oleh Muhammad (Abu al-Hasan) bin al-Husain (Abi Ahmad ath-Thahir), keturunan Imam Musa bin Imam Ja'far ash-Shadiq yang diberi gelar dengan Syarif Radhi. Ia lahir pada tahun 359 H di Baghdad pada masa Khalifah al-Muthi' al-Abbasi (334-363 H), dimana Khalifah al-Abbasi hanya sebagai simbol semata, sedang yang berkuasa adalah Bani Buwaih (Syiah). Irak saat itu dikuasai oleh Izz ad-Daulah Bakhtiyar bin Muiz ad-Daulah bin Abu Syuja' Buwaih.

Syarif Radhi mewarisi kehebatan dan kedudukan ayahnya, dan menimba ilmu dari banyak ulama besar di zamannya hingga dia menjadi tokoh Syiah terkemuka, tokoh Mu'tazilah, sekaligus penyair tertinggi bersama kakaknya 
Syarif Murtadha, Ali (Abu al-Qasim) bin Husain (Abu Ahmad ath-Thahir) (355-436 H).

Para ulama sepakat bahwa Syarif Radhi adalah penganut akidah Syiah Imamiyyah sekaligus Mu'tazilah, yang ghuluw kepada duabelas imam Syiah, dan membenci serta menolak Abu Bakar, Umar dan Usman r.a. yang dia anggap sebagai perampas dan perampok hak khilafah. Imam ad-Dzahabi dalam kitab al-Musytabih berkata: "Syarif Radhi adalah seorang penyair yang mufliq (bagus syair-syairnya) (Abduh, t.t: 16), berakidah Syiah Imamiyyah" (Dimasyqi, 1993: 9/190). Akhirnya pada 6 Muharam 406 H Syarif Radhi wafat di Baghdad dalam usia 47 tahun (Hadid, 1965: 40).

\section{Kedudukan Nahj al-Balaghah di Kalangan Kaum Syiah}

Nahj al-Balaghah menempati kedudukan tinggi di kalangan Syiah. Beberapa data yang dapat menjelaskan hal ini antara lain:

1. Nahj al-Balaghah diyakini sebagai kitab Hadis dan seluruh isinya sahih, mengingkarinya sama dengan mengingkari hadis Nabi saw. Yayasan al-Baqir Bangil Pasuruan menerbitkan buku berjudul "560 Hadis dari 14 Manusia Suci”, dan menjadikan Nahj al-Balaghah sebagai rujukan utama (Guven, 1995: 57-73). Al-Hadi Kasyif al-Ghitha' al-Najafi (1289-1361 H) berkata dalam Mustadrak Nahj al-Balaghah (Qifari, 1414: 1/389):

Sesungguhnya Syiah, meskipun banyak sekte dan berselisih namun mereka semua bersepakat dan menerima bahwa semua yang ada di dalam Nahj alBalaghah adalah berasal dari ucapan Amirul Mukminin Ali r.a., karena percaya kepada riwayat Syarif Radhi dan pemahamannya serta ke-tsiqahan-nya, hingga hampir saja menurut mereka pengingkaran penisbatannya kepadanya r.a. termasuk mengingkari dharuriyyat dan badihiyyat, keadaannya sama dengan apa yang diriwayatkan dari Nabi saw. (Ghitha, t.t.: 90-91, Qifari, 1414: 1/472).

2. Nahj al-Balaghah berisi Islam sejati (hakiki). Situs yang berafiliasi kepada Grand Ayyatallah Mousawi Ardebili menjelaskan bahwa lahirnya Kitab Nahj al-Balaghah dilatarbelakangi oleh keinginan Syarif Radhi memperkenalkan "agama Islam yang sesungguhnya" kepada semua orang di dunia dengan cara mengenalkan Syiah sejati (Dimyati, t.t).

3. Nahj al-Balaghah adalah kitab ilahi, paling penting setelah al-Quran yang wajib dibaca dan menjadi rujukan penting bagi kaum Syiah. Muhammad al-Husain al-Kasyif al-Ghitha menyebutnya sebagai al-Sifr al-'Azhim la tsani lahu ba'da Kitab Allah (Kitab Agung tidak ada duanya setelah al-Quran) Zahra, 1405: 1/11). Pemimpin Revolusi Syiah Iran Ayatullah Khumaini dalam Kongres Nahj al-Balaghah) 27/2/1360 HS berkata bahwa Nahj 
al-Balaghah adalah "Kitab Ilahi" (Qummi: t.t.). Pemimpin revolusi Syiah Iran itu berwasiat:

Kami bangga bahwa kitab Nahj al-Balaghah yang ia adalah dustur terbesar untuk kehidupan materi dan immateri setelah al-Quran, dan Kitab tertinggi untuk membebaskan manusia, dan ajarannya yang bersifat nilai (norma) dan hukum pemerintahan dan merupakan manhaj kehidupan yang paling luhur adalah berasal dari imam kami yang ma'shum. Kami bangga bahwa para imam yang ma'shum mulai dari Ali bin Abi Thalib hingga penyelamat manusia Imam Mahdi Shahib al-zaman (imam Zaman ini) -semoga Allah memberi beribu-ribu penghormatan dan salam- yang dengan kekuasaan Allah yang Maha kuasa dia hidup dan memperhatikan segala urusan ... (Khumaini, t.t; Anonim (Kedubes Iran di Jakarta), t.t.: 79).

4. Nahj al-Balaghah itu berada di atas ucapan semua makhluk. Abu al-Qasim al-Khu'i, pimpinan Syiah Najaf Irak berkata: "Sungguh sebaik-baik yang dikatakan dalam menjelaskan sifat Nahj al-Balaghah adalah: dia itu di bawah ucapan Yang Maha mencipta dan di atas ucapan para makhluk.” (Khu'i, t.t.).

\section{Gambaran dan Isi Nahj al-Balaghah}

Nahj al-Balaghah berisi kumpulan khotbah, surat, wirid, mau'izhah, adab, doa dan ucapan-ucapan hikmah yang dinisbatkan kepada Ali r.a. tanpa ada sanadnya. Kriteria seleksi penuturan-penuturan Khalifah Ali ini adalah sastra kefasihan dan balaghah. Nahj al-Balaghah disusun dalam tiga bagian: Khotbah-khotbah (Pidato-pidato), surat-surat, dan kata-kata mutiara (hikmah).

Kitab Nahj al-Balaghah berisi: 239 khotbah, 79 surat dan 478 hikmah (Abduh, t.t). Ada yang mengatakan 238 khotbah, 79 surat dan 489 ucapan hikmat. Atau 238 Khotbah, 79 surat dan 488 kata hikmat (Jabir, 1987). Ada pula yang menghitung: 241 Khotbah, 79 surat dan 480 kata mutiara. Syarif Radhi berusaha memilih hadis-hadis Alawi yang paling indah, fashih dan baligh. Maka inilah rahasia kekekalan kitab Nahj al-Balaghah ini dan yang menjadikannya terkenal.

\section{Konsep sanad dalam Nahj al-Balaghah}

Setelah peneliti melakukan kajian terhadap kitab Nahj al-Balaghah, ternyata kitab yang diagungkankan ini tidak memiliki konsep sanad dan riwayat-riwayatnya juga tanpa sanad. Sementara jarak antara Syarif Radhi dengan Imam Ali hampir 4 abad, dan Syarif Radhi sendiri seorang yang ghuluw 
dalam mengkultuskan imam dan memusuhi sahabat. Riwayat orang seperti ini tidak diterima dalam ilmu Rijal milik Ahlussunnah. (Asqalani, 1326: 1/94).

Di dalam Nahj al-Balaghah ada satu klaim yang menyindir Ahlussunnah yang meriwayatkan dengan sanad dan dianggap tidak memahami kandungannya. Perhatikan sifat Ahlul Bait berikut ini, setelah Imam Ali menceritakan Ahlul Bait sebagai rujukan dalam agama dan ma'shum dia mengatakan:

"Mereka (Ahlul Bait itu) memahami agama ini dengan pemahaman yang mewadahi dan memelihara, bukan pemahaman mendengar dan meriwayatkan, sebab para perawi ilmu itu banyak, sedangkan pemeliharanya sedikit" (Abduh, t.t.: 283, no. 237).

Ucapan yang bagus ini tidak ada bukti yang didukung oleh sanad sebagai ucapan Imam Ali, yang ada sanadnya justru ucapan sahabat Abdullah bin Masud r.a. Misalnya, Abu Nuaim meriwayatkan dengan sanad-nya yang muttashil hingga Ibnu Mas'ud bahwa dia berkata, "Jadilah bagi ilmu itu sebagai pemelihara, dan jangan menjadi hanya sebagai perawi, sebab terkadang orang itu menjaga diri (memelihara) tapi tidak meriwayatkan, dan ada yang meriwayatkan tapi tidak menjaga diri (memelihara)" (Nuaim, 1974: 7/262; Barr, 1994: 1/696, no. 1238; Anzi, 2010).

Ini membuktikan bahwa sebagian isi Nahj al-Balaghah adalah bukan dari ucapan Imam Ali melainkan dari ucapan orang lain yang diatasnamakan Imam Ali karena keindahannya. Nahj al-Balaghah tidak memiliki sanad kepada Imam Ali a.s. bahkan kitab-kitab hadis yang menjadi sumber rujukannya juga tidak ada atau tidak disebut, yang disebut adalah kitab atau risalah bahasa, sastra dan sejarah atau hikayat, itupun hanya di sebelas tempat. Yang disebut misalnya kitab al-Bayan wat-Tabyin, karya al-Jahizh al-Mu'tazili, kitab al-Maqamat karya Abu Ja'far al-Iskafi al-Mu'tazili, al-Muqtadhab karya al-Mubarrid, al-Maghazi karya Said bin Yahya al-Umawi, al-Jamal karya al-Waqidi, Tarikh Ibnu Jarir ath-Thabari, Hikayat Abi Ja'far Muhammad bin Ali al-Baqir, Riwayat al-Yamani dari Ahmad bin Qutaibah, buku dengan tulisan tangan Hisyam bin al-Kalbi, Cerita Dhirar bin Hamzah al-Dhiba'i/al-Shada'i, Riwayat Abu Juhaifah, Hikayat Tsa'lab dari Abu al-A'rabi.

Kitab Nahj al-Balaghah yang tanpa sanad ini menerangkan bahwa manusia yang meriwayatkan hadis dibagi menjadi empat: munafik (ini membuat hadis palsu, dusta atas nama Rasulullah saw.), mukhthi` (meriwayatkan salah, berbeda dengan yang disampaikan Rasulullah saw. karena tidak hafal), ahli syubhat (mendengar Nabi memerintah sesuatu kemudian tidak mengetahui kalau Nabi setelah itu melarang atau kebalikannya. Seandainya dia mengetahui bahwa apa yang dihafalnya itu mansukh nicaya dia menolak, begitu pula kalau 
umat Islam mengetahui karena mendengarnya darinya niscaya menolaknya), dan shadiqun hafizhun yaitu jujur, bertakwa, tidak berdusta, tidak salah, hafal apa yang dia riwayatkan sesuai dengan maksudnya, tidak menambahnya dan tidak menguranginya, menghafal nasikh lalu mengamalkannya, hafal mansukh lalu menjauhinya, mengerti yang khash dan yang 'am, dia meletakkan segala sesuatu pada tempatnya, mengerti mutasyabih, yaitu ucapan yang samar, hanya Allah dan ulama rasikhun yang mengerti maksudnya; dan muhkam-nya, yaitu nash yang jelas dan tidak di mansukh.

Kemudian setelah itu Syarif Radhi menutup dengan ucapan, "Inilah bentuk-bentuk yang ada pada manusia dalam perbedaan mereka dan penyakit-penyakit mereka dalam riwayat mereka." Jika dihubungkan dengan akidah imamah dan "ishmah bagi Ahlul Bait maka Syiah diposisikan sebagai kelompok keempat yaitu orang yang mewadahi ilmu Allah dan Rasul-Nya, tanpa transmisi para perawi yang menurut mereka banyak dusta dan salah itu.

\section{Hasil Analisa}

Konsep Isnad ini diterapkan pertama kali oleh Abu Bakar ash-Shiddiq (Jabbar, t.t.: 1/47; Suyuthi, t.t.: 1/257; Hisyam, 1955: 1/399), dan oleh para sahabat r.a maka konsep Isnad ini diterapkan di tengah umat Islam tatkala muncul para ahlul bid'ah tahun $35 \mathrm{H}$, saat terbunuhnya Khalifah Usman r.a. sebagaimana diceritakan oleh Muhammad bin Sirin (w. 110 H) dalam Shahih Muslim. Ini menunjukkan bahwa ketika hadis itu beredar di tengah-tengah Sahabat saja, mereka saling memberitahu dan tidak perlu bertanya tentang isnad, karena semua Sahabat adil yang artinya shalih dan dipercaya, berdasarkan nash dari Allah, Sunnah dan Ijma' (Baghdadi, t.t: 1/46; Shalah, 1986: 1/292).

Imam asy-Syafi'i mengilustrasikan pentingnya sanad ini dengan mengatakan, "Barangsiapa tidak bertanya dari mana? Maka dia seperti pencari kayu bakar di malam hari, memanggul seikat kayu bakar di punggungnya, barang kali di dalamnya ada ular yang mematuknya" (Jurjani, 1997: 1/206). Sebagai aplikasinya, apabila disebutkan kepada Imam asy-Syafi'i satu hadis yang tidak dia kenal, maka dia berkata: "Buktikan kesahihannya (tsubut-nya) hingga saya mengikutinya" (Mawardi, 1999: 10/19).

Setelah itu Imam asy-Syafi'i berkata, "Semua ilmu (agama) selain alQuran ini menyibukkan, kecuali hadis dan ilmu fikih dalam agama. Ilmu itu adalah apa yang ada haddatsana di dalamnya (ada sanad-nya), selain itu adalah waswas setan” (Syafi'I, 2010: 106; Subki, 1413: 1/297; Katsir, 2004). Al-Husain bin Ali al-Karabisi berkata, "Imam asy-Syafi'i berkata: Semua orang 
yang berbicara atas dasar al-Quran dan as-Sunnah maka dia serius, selain itu adalah hadzayan (igauan)" (Katsir, 2004; Muthraji, t.t.: 1/14).

Dengan demikian menurut pandangan dan manhaj Imam asy-Syafi'i, kitab Nahj al-Balaghah berisi campuran antara kayu bakar dan ular, berisi waswas setan dan igauan, kecuali bagian isinya yang terbukti benar. Maka kitab Nahj al-Balaghah tidak bisa begitu saja menjadi hujjah. Al-Hafizh Ibnu Abdil Barr berkata: "Hujjah itu dari segi sanad, diperketat dalam hal hukum dan dalam hal halal dan haram" (Barr, 1994: 1/152).

\section{Ajaran Nahj al-Balaghah}

Karena Nahj al-Balaghah tidak memiliki sanad yang shahih sampai kepada sayyidina Ali maka banyak isinya yang bertentangan dengan Islam, Nabi, Sahabat dan Ahl al-Bait. Berikut ini beberapa contoh kebatilan klaim Nahj al-Balaghah:

\section{Contoh Sanad Syiah}

Khotbah yang paling terkenal adalah Syiqsyiqiyyah (no. 3 dalam kitab Nahj al-Balaghah), yang isinya menolak Khalifah Abu Bakar, Umar, dan Usman dan menuduh mereka merampas hak Ali r.a. Di situ dikatakan Imam Ali bersabda:

"Ingatlah, demi Allah, khilafah itu telah dipakai oleh fulan (Abu Bakar), padahal dia tahu kedudukanku darinya seperti kedudukan quthub dari penggilingan, (yang mana) air bah turun menjauh dariku dan burung tidak bisa naik kepadaku." (Abduh, t.t.: 33).

Khotbah ini, dengan redaksi ini tidak benar dari ucapan Ali r.a. Ghuwaid bin Syabab bin Shaleh al-Ghamidi telah mengkritisinya, intinya sebagai berikut:

a. Dari segi sanad

1) Syarif Radhi tidak menyebut sanad dan sumbernya, seperti biasa.

2) Orang Syiah kalau diminta sanad riwayat-riwayat Nahj al-Balaghah selalu merujuk kepada kitab Mashadir Nahj al-Balaghah Wa Asaniduhu karya Abd az-Zahra' al-Khathib, padahal kitab ini sudah terbukti tidak bisa menjadi hujjah (Ghamidi, 2012: 222).

3) Saat merujuk ke kitab Abd az-Zahra', kita mendapatkan dia menyebutkan 16 sumber (Ghamidi, 2012: 223-224; Khatib, 1988: 1/309-312).

Melihat banyaknya yang disebut sebagai sumber, maka pembaca 
akan mendapatkan kesan ini valid, namun ternyata semuanya tidak bermakna, tidak berkualitas, banyak yang dijadikan sebagai sumber itu orang-orang yang hidup setelah Syarif Radhi. Ghuwaid membahas satu persatu apa yang disebut oleh Abd az-Zahra' dan membantahnya, dengan banyak merujuk kepada Ala ad-Din alBashir penulis kitab Usthurah al-Khothbah asy-Syiqsyiqiyyah yang membantah dan membuktikan kebatilan khotbah Syiqsyiqiyyah, bahkan memberikan tantangan terbuka kepada Syiah sedunia jika bisa mendatangkan sanadnya (Ghamidi, 2012: 230-233).

b. Dari segi matan

Adapun dari segi matan maka mustahil khotbah ini berasal dari Imam Ali, sebab isinya adalah kufur yaitu menetapkan imamah ma'shumah untuk dirinya dan menetapkan pengkhianatan dan kekufuran bagi Khalifah Abu Bakar, Umar, dan Usman. Ghuwaid membantah matan khotbah ini sampai sembilan poin (Ghamidi, 2012: 234-237).

2. Contoh Sanad Mu'tazilah

Khotbah nomor satu pada Nahj al-Balaghah berisi salah satu dari lima Ushul Mu'tazilah, bahkan yang paling inti, yaitu Ta'thil ash-Shifat yang sampai pada kesimpulan "Al-Quran itu makhluq". Diantara isi khotbah ini adalah:

"Permulaan agama ini adalah mengenal-Nya Dan kesempurnaan mentauhidkan-Nya adalah ikhlas kepadanya, dan kesempurnaan ikhlas kepadanya adalah mengingkari sifat-sifat-Nya, sebab kesaksian setiap sifat bukanlah yang menyandang sifat, dan kesaksian setiap yang menyandang sifat bukanlah sifat itu." (Abduh, t.t.: 25).

Apakah benar ini ajaran Imam Ali r.a? Adakah Sanadnya?

a. Dari segi sanad

1) Khotbah ini panjang, lebar dan sulit, tidak mungkin seseorang bisa menirukannya dengan lafalnya tanpa ada tulisan di hadapannya, namun demikian Syarif Radhi menghadirkannya tanda sanad dan tanpa sumber.

2) Abd az-Zahra' al-Khathib menyebutkan bahwa sumbernya adalah Ali bin Muhammad bin Syakir al-Wasithi dalam kitab 'Uyun al-Mawa'izh wa al-Hikam, az-Zamakhsyari dalam Rabi' alAbrar, al-Quthub ar-Rawandi dalam Syarah Nahj al-Balaghah, Ibnu Syu'bah dalam Tuhfah al'Uqul, Muhammad bin Thalhah asySyafi'i dalam Mathalib as-Sa'ul, Ibnu Manshur Ahmad bin Abi 
Thalib ath-Thabarsi dalam al-Ihtijaj, Muhammad bin Salamah yang dikenal dengan Qadhi al-Qudhat dalam Dustur Ma'alim al-Hikam, dan Tafsir ar-Razi menyebut sebagiannya (Ghamidi, 2012: 658).

3) Tafsir ar-Razi, Kitab Dustur Ma'alim al-Hikam, kitab Mathalib al-Sa'ul, al-Ihtijaj, Tuhfah al'Uqul, Syarah Nahj al-Balaghah milik Rawandi, Rabi' al-Abrar milik Zamakhsyari maka tidak layak menjadi sumber yang benar bagi khotbah ini, karena sebabsebab yang sudah dijelaskan.

4) Kitab 'Uyun al-Mawa'izh wa al-Hikam karya Ali al-Wasithi (457 $\mathrm{H})$, lebih buruk lagi keadaannya, sebab: tidak disebut sanadnya, sangat berbeda dengan yang ada dalam Nahj al-Balaghah, sangat sedikit, mungkin pembicaraan lain tidak ada kaitannya dengan Nahj al-Balaghah, penulisnya lebih muda dari Syarif Radhi.

Klaim Abd az-Zahra' bahwa khotbah ini dihafalkan oleh para Imam, disebut dalam ucapan-ucapan mereka, adalah ucapan yang tidak berdasar sama sekali.

b. Dari segi matan

Ghuwaid bin Syabab mematahkan matan riwayat ini sebagai berikut:

1) Dalam khotbah ini ada banyak kata sulit, makna yang asing dan sajak yang dipaksakan, tidak dikenal di masa sahabat apalagi di lisan para Khalifah ar-Rasyidun.

2) Khotbah ini mengandung kata atau istilah muwallad (baru dimunculkan) seperti "al-Juz, al-hadd, al-wujud" dan sejenisnya yang tidak terdapat kecuali di zaman Abbasi saat diterjemahkannya filsafat.

3) Pendahuluan khotbah panjang, ini hanya dikenal di masa Abbasi (di masa Syarif Radhi) di khotbah Jumat atau hari raya.

4) Kalimat "permulaan agama adalah mengenalnya .... Ini adalah makalah Mu'tazilah, bahwa kewajiban mukallaf pertama kali adalah nazhar untuk ma'rifat pada pencipta, bukan membaca dua kalimat syahadat sebagaimana Ahlussunnah.

5) Inti khotbah mengajak untuk ta'thil, menolak Sifat-sifat Allah. Ini adalah Mu'tazilah mengambil dari Jahmiyyah. Washil bin 'Atha' pelopor Mu'tazilah menafikan sifat dari Allah karena beranggapan bahwa menetapkan sifat berarti menetapkan 
berbilangnya yang Qadim, yang berarti syirik, oleh karena itu dia mengatakan: "Barangsiapa menetapkan makna sifat yang dahulu maka dia telah menetapkan adanya dua tuhan" (Syaharastani: $1 / 46)$.

Inilah yang dimaksud oleh Imam Syafi'i dalam ucapannya: "Tidaklah manusia menjadi bodoh dan berselisih kecuali karena mereka meninggalkan bahasa Arab dan condong kepada bahasa Aristotles" (Dzahabi: 8/268; Suyuthi: 15).

6) Di dalam khotbah ini terdapat bid'ah Syiah tentang imamah setelah Nabi saw. Ini jelas susupan untuk melayani sektenya.

7) Ketika merujuk ke kitab Mu'tazilah, mereka menyebutkan bahwa I'tizal itu sudah ada sebelum Washil Bin Atha', bahkan I'tizal ini berasal dari ajaran Ali bin Abi Thalib, bahkan putranya Muhammad bin al-Hanafiyyah mengambil madzhab ini dari ayahnya kemudian diwariskan ke putranya Abu Hasyim gurunya Washil. Maka Ibnu al-Murtadha az-Zaidi menisbatkan Imam Ali kepada I'tizal. (Segaf, tt).

Ini semakin memberi petunjuk bahwa sekte-sekte ini selalu menolak riwayat yang ada (yang sahih), dan membuat riwayat palsu untuk melayani alirannya. Ini karena klaim Imam Ali sebagai Mu'tazilah hanya ada di dalam kitab Mu'tazilah, dan sanadnya tidak sahih, berarti berasal dari buatan mereka.

Seorang tokoh Khawarij, setelah bertaubat memberikan peringatan tentang pentingnya sanad dan pengakuan bahwa ahli bid'ah membuat hadis palsu: "Hadis-hadis ini adalah agama maka lihatlah dari mana kalian mengambil agama kalian. Sesungguhnya kami dulu apabila menyukai sesuatu maka menjadikannya sebuah hadis (Baghdadi: $1 / 123,128$ ).

Inilah Syiah Rafidhah, fakta yang ada mereka tolak, dan sesuatu yang tidak ada mereka ada-adakan. Sosok Ibnu Saba' al-Yahudi yang mencetuskan bid'ah al-washiyyah untuk Imam Ali dan bara'ah dari para sahabat itu ada tapi mereka berusaha menolaknya. Dalam buku Ibn Saba' al-Syabah al-Mukhif dijelaskan bahwa ada dua sosok Abdullah ibn Saba', yang satu dibakar Imam Ali dan yang satu diusir ke Madain (Bashir, 1429: 470-471). Hadis-hadis musnadah (yang ada sanadnya), ijma' terhadap baiat Abu Bakar, dan Mushhaf Usmani mereka tolak. Sementara yang tidak ada mereka ada-adakan, misalnya khotbah Imam Ali yang menghujat (melaknat, mengkafirkan) Abu bakar, Umar, Usman, Aisyah, Talhah, Zubair dan para sahabat, adanya Imam Mahdi Syiah, dan mazlumiyyat Fatimah (kezaliman-kezaliman yang ditimpakan kepada Fatimah). 
Fikih madzhab Ja'fari juga tidak ada, dia tidak memiliki kitab fikih sebagaimana imam madzhab empat. Maka Syaikh Thaha al-Dulaimi menulis kitab Usthurah al-Madzhab al-Ja'fari untuk membela Imam Ja'far ini. Ibn Abd al-Barr mengatakan: "Imam Shadiq itu dikenal tsiqah dan terpercaya, cerdas, bijak, wira'i, utama, kepadanya Ja'fariyyah dinisbatkan, orang-orang Syiah Imamiyyah mengklaimnya. Syiah banyak berdusta atas namanya." (Barr, 1387: 2/66).

Karena tidak memiliki sanad dan sumber, namun sudah mengklaim dan mendeklarasikan dirinya sebagai satu-satunya yang sah dan benar maka muncul kejanggalan, yaitu, orang Syiah yang datang setelah masa Syarif Radhi berusaha mentakhrij hadis-hadis Nahj al-Balaghah dari sumber-sumbernya, dan sudah diumumkan bahwa semua isi Nahj al-Balaghah benar, ternyata banyak hadis yang sumbernya justru umurnya lebih muda dari pada Nahj al-Balaghah, dan itupun banyak yang tidak nyambung dengan yang ada di dalam Nahj al-Balaghah. Benar kata Imam al-Auza'i: "Tidaklah ilmu itu hilang kecuali dengan hilangnya sanad” (Barr, 1387: 1/57). Maka hilanglah ilmu dari tangan orang Syiah karena mereka kehilangan sanad kepada Rasulullah S.A. dan para sahabatnya.

Berdasarkan fakta di atas maka Nahj al-Balaghah bukanlah sumber ilmu dalam bidang agama, akidah, hadis, sejarah sahabat, dan akhlak kepada salaf shalih, tetapi ia adalah ilmu dalam bahasa, sastra, dan ilmu-ilmu alam dan sosial yang harus ditimbang isinya dengan al-Quran dan as-Sunnah.

3. Contoh ajaran bara'ah (berlepas diri) dari para Istri Nabi dan para sahabat karena diklaim mereka memusuhi Ali.

Nahj al-Balaghah mengatasnamakan kepada Imam Ali, menanamkan sikap bara'ah terhadap para sahabat Nabi saw. Dikatakan Imam Ali berkata, "Saya senantiasa terzalimi sejak Rasulullah saw. wafat." (Abduh, t.t.: 99). "Demi Allah, aku tidak henti-hentinya dihalangi dari hakku, direbut hakku, sejak Allah mencabut nyawa Nabi-nya saw. hingga zaman manusia hari ini" (Radhi, 1406: 39).

Dari sini maka para sahabat dan masyarakat muslim zaman para khalifah ar-Rasyidun dan khususnya zaman Muawiyah digambarkan oleh Nahj alBalaghah sebagai: mariqun (keluar dari agama), nakibun (menyimpang), nakitsun (murtad), khainun (pengkianat), murtabun (orang yang bimbang), munafiqun (menyembunyikan kekufuan), dhallun (sesat), maftunun (terfitnah), mufariqun (memisahkan diri) (Muhammadi, 2009: 3-4).

el Harakah Jurnal Budaya Islam Vol.18 No.2 Tahun 2016 
Di buku kisah-kisah Nahj al-Balaghah yang di sampulnya ditulis "Keputusan Direktur Jenderal Pendidikan Islam nomor Dj.1/375/2009.” dikatakan: Muawiyyah yang termasuk qasithun (kaum durhaka) itu memperluas wilayahnya dengan represif dan teror dan pembantaian, durjana dan kejam (Muhammadi, 2009: 4, 18, 20, 28-29). Muawiyah adalah peletak batu pertama bid'ah cercaan (pelaknatan) terhadap imam Ali (Muhammadi, 2009: 56-57). Amr bin Ash menjual agama kepada Muawiyyah (Muhammadi, 2009: 22). Talhah dan Zubair adalah kelompok nakitsun (Muhammadi, 2009: 4), menyusun makar busuk untuk menentang Imam Ali (Muhammadi, 2009: 11). Talhah itu zalim penghasut (Muhammadi, 2009: 31). Sahabat nabi Asya'ats ibn Qais al-Kindi adalah pemimpin orang-orang munafiq di masa Imam Ali (Muhammadi, 2009: 15, 37). Nu'man bin Basyir r.a. adalah penjilat dan pendukung penguasa zalim Muawiyah (Muhammadi, 2009: 34).

Dalam buku Mutiara Sastra Nahj al-Balaghah Edisi Surat dan Aforisme terbitan al-Huda, ICC (Islamic Cultural Center) Jakarta, ditulis bahwa Muawiyah pemberontak untuk merebut kekuasaan (Muhammadi, 2009: 6365), pengabdi kebatilan, seluruh hidupnya menindas kebenaran, pembuat bencana, munafik (Muhammadi, 2009: 71), masuk Islam pura-pura karena terpaksa (Muhammadi, 2009: 92), Muawiyyah adalah setan yang mendekati orang mukmin dari depan dan belakang, dari kanan dan kiri (Muhammadi, 2009: 133), Aisyah adalah musuh dan pemberontak secara terang-terangan (Muhammadi, 2009: 29). Sahabat Nabi saw. ini dihukumi murtad karena mengangkat Abu Bakar sebagai Khalifah, mengkhianati Nabi dan Ahl baitnya (Muhammadi, 2009: 147).

Dengan fakta ini maka terbuktilah bahwa Syarif Radhi adalah seorang Syiah Rafidhah Imamiyyah yang ekstrim, bukan moderat sebagaimana disinggung oleh Muhammad Rasyid Ridha Al-Husaini (1947: 1/10). Imam Syafi' i berkata, "Barangsiapa mengatakan Abu Bakar dan Umar bukan imam maka dia seorang Rafidhah (Syiah ekstrim)” (Dzahabi, 2006: 10/31; Harawi, 1998: 4/308).

Klaim-klaim Nahj al-Balaghah tanpa sanad ini dan dinisbatkan kepada Khalifah Ali ini bertentangan dengan al-Quran, Hadis-hadis sahih, dan fakta sejarah yang mana Imam Ali dan Ahlul Bait berbaiat kepada para khalifah ar-Rasyidin, menjadi menteri dan penasehat mereka, mengadakan hubungan perbesanan dengan mereka dan memberi nama putra-putranya dengan nama Abu bakar, Umar, Usman, dan Aisyah. 


\section{Simpulan}

Kitab Nahj al-Balaghah tidak memiliki sanad. Semua hadis alawi dalam Kitab Nahj al-Balaghah (239 khotbah, 79 surat, dan 478 hikmah, atau 238 khotbah, 79 surat, dan 489 ucapan hikmat, atau 238 Khotbah, 79 surat dan 488 kata hikmat. Atau 241 Khotbah, 79 surat dan 480 kata mutiara) disampaikan oleh Syarif Radhi (359-306 H) tokoh Rafidhah dan Mu'tazilah dari Imam Ali tanpa sanad, sementara jarak antara dia dan Imam Ali hampir 4 abad. Nahj al-Balaghah itu sendiri tidak memuat konsep sanad, dan tidak dibangun dengan sanad, sehingga ada ucapan indah diklaim sebagai ucapan Imam Ali padahal berdasarkan sanad yang muttashil, ucapan yang mirip dengan itu berasal dari Ibnu Mas'ud.

Nahj Balaghah berisi akidah Tasyayyu' Ghali (Syiah Rafidhah) yaitu mengkultuskan Imam Ali dan 11 Imam berikutnya, dan berisi akidah bara'ah (berlepas diri) dari Khalifah Abu Bakar, Umar dan Usman, serta memusuhi para sahabat Nabi Muhammad saw. Nahj al-Balaghah menggambarkan Khalifah Abu Bakar, Umar dan Usman, Aisyah istri Nabi, Abu Hurairah, Talhah, Zubair dan Muawiyah sebagai sahabat Nabi yang buruk, pengkhianat dan murtad. Disamping itu Nahj al-Balaghah juga berisi akidah Mu'tazilah.

\section{Rekomendasi}

Kitab Nahj al-Balaghah yang kesohor sebagai kitab sastra yang menyihir banyak orang karena keindahan bahasanya dan keluasan cakupan temanya, serta karena dinisbatkan kepada Imam Ali bin Abi Thalib, ternyata memuat ghuluw kepada sebagian Ahlul Bait dan kebencian yang serius kepada khulafa ar-Rasyidin sebelum Ali, kepada Ummahatul Mukminin dan kepada Para sahabat Nabi yang lain. Hal itu semua diatas namakan kepada Imam Ali tanpa sanad. Mengingat penemuan penelitian ini penting, maka peneliti merekomendasikan agar: Pertama, umat Islam diperingatkan dari kesalahannya, dan tetap memposisikan Nahj al-Balaghah sebagai kitab sastra bukan kitab hadis. Kedua, kegiatan tabayyun ilmiah ini digalakkan supaya menjadi biasa dan membudaya sebagai ciri khas Ahlussunnah wa al-Jamaah. Imam Syafi'I berkata: Jika kalian melihat ada orang yang bisa berjalan di atas air dan terbang di udara maka jangan terkecoh dengannya hingga kalian menimbangnya dengan al-Quran dan as-Sunnah."

el Harakah Jurnal Budaya Islam Vol.18 No.2 Tahun 2016 


\section{Daftar Pustaka}

Anonim, t.t. Sekilas Tentang Imam Khomeini. tanpa penerbit. (Jakarta: Kedubes Iran).

Anshari, Zakariya al-Anshari. t.t. Fath al-Baqi 'Ala Alfiyah al-'Iraqi. Beirut: Dar al-Kutub al-Ilmiyyah.

Asqalani, Ahmad ibn Ali Ibn Hajar al-. t.t. Nuzhah al-Nazhar. Mesir: Mushthafa al-Babi al-Halabi wa Awladuhu.

, 1326, Tahdzib al-Tahdzib. India: Mathbaah Dairah al-Ma'arif alNizhamiyyah.

Abduh, Muhammad. t.t. Syarah Nahj al-Balaghah. tahqiq Muhammad Ahmad Asyur, Dar Mathabi' al-Sya'b.

Anzi, Abu Abdillah ibn Jafil al-. 2010. Ma huwa Takhrij Atsar Kunu li al-ilmi ru'at. http://www.ahlalhdeeth.com/vb/showthread.php?t=249510, (1 Agustus 2016).

Baghdadi, Abu Bakar al-Khatib al-. t.t. Al-Kifayah fi 'Ilm al-Riwayah. tahqiq al-Suraqi dan al-Madani, Madinah: Maktabah al-Ilmiyya.

Barr, Abu Umar Yusuf ibn Abd al-. 1994. Jami' Bayan al-'Ilmi wa Fadhlih, Tahqiq Abu Al-Asybal, Saudi Arabia: Dar Ibn al-Jauzi.

, 1387. al-Tamhid Lima fi al-Muwaththa`Min al-Ma'ani wa al-Masanid. Maghrib: Wizarah al-Auqaf wa al-Syu`un al-Islamiyyah.

Bashir, Ala` al-Din al-. 1429. Ibn Saba`al-Syabah al-Mukhif, al-Thiba'ah al'Ashriyyah.

Bashori, Agus Hasan, 2016, Studi Kritis Konsep Ilmu Dalam Kitab Nahj al-Balaghah dan Relevansinya dalam Penguatan Pendidikan Agama Islam di Tingkat Sekolah Dasar, Disertasi Program Doktor Pendidikan Islam UIKA Bogor.

Bukhari, Muhammad ibn Ismail al-. 1422. Al-Jami' al-Musnad al-Shahih, Ta'liq: Mushthafa Dib al-Bugha. Dar Thauq al-Najah.

Dimasyqi, Muhammad al-Qaisi al-. 1993. Taudhih al-Musytabih fi Dhabt Asma al-Ruwah. Beirut: Muassasah al-Risalah.

Dzahabi, Syamsuddin Al-. 2006. Siyar A'lam al-Nubala', Kairo: Darul hadits. 
Dimyati, Nashir. t.t. Syarif Radhi, http://www.sadeqin.net/ml/daneshvaran. php? mod $=4 \& i d=16$ (2 September 2015).

Fayyadh, Ahmad Ayyub Muhammad Abdullah al-. 2007. Mabahits Fi al-Hadits al-Musalsal, Beirut: al-Kutub al-Ilmiyyah.

Ghamidi, Ghuwaid ibn Syabab al-. 2012. Kitab Nahj al-Balaghah Dirasah Naqdiyyah 'Aqadiyyah, Makkah: Ummul Qura.

Guven, Fatih. 1995. 560 Hadis dari 14 manusia Suci. Bangil: Yayasan Islam al-Baqir.

Ghitha, Al-Hadi Kasyif al-. t.t., Mustadrak Nahj al-Balaghah, tanpa penerbit (Maktabah Ahl al-Bayt)

Hadid, Ibn Abi al-, 1997. Syarah Nahj al-Balaghah, Dar Ihya `al-Turats al-'Arabi, Tahqiq: Muhammad Abu al-Fadhl Ibrahim.

Harawi, Abu Ismail al-, 1998, Dzamm al-Kalaf wa Ahlih, Madinah Munawwarah: Maktabah al-Ulum wa al-Hikam.

Hindi, Rahmatullah al-, t.t. Izhhar al-Haq, tahqiq: Muhammad Ahmad Malkawi, al-Riasah 'ammah li Idarat al-Buhuts, Saudi.

Hisyam, Abdul Malik ibn. 1955. al-Sirah al-Nabawiyyah, tahqiq: Mushthafa Saqa dkk, Mesir: Syarikah Mushthafa al-babi al-Halabi.

Jabir, Qasim Habib. 1987. Al-Falsafah wa al-I'tizal Fi Nahj al-Balaghah. al-Muassasat al-Jami'iyyah li al-Dirasat wa al-Nasyr.

Jabbar, Al-Qadhi Abdul. t.t. Tatsbit Dalail al-Nubuwwah, Kairo: Dar al-Mushthafa, Syabra.

Jurjani, Abu Ahmad ibn Adi al-. 1997. Al-Kamil fi Dhu'afa`al-Rijal,tahqiq: Adil Ahmad Abdul Maujud dkk, Beirut: al-Kutub al-Ilmiyyah.

Jama'ah, Badruddin Muhammad ibn. t.t., al-Manhal al-Rawiy Fi Mukhtashar Ulum al-Hadits, Beirut: Dar al-Fikr

Khatib, Abd az-Zahra' al-. 1988. Mashadir Nahj al-Balaghah wa Asaniduh, Beirut: Dar az-Zahra'.

el Harakah Jurnal Budaya Islam Vol.18 No.2 Tahun 2016 
Khumaini, Al-Imam al-. t.t. Al-Washiyyah al-Ilahiyyah al-Siyasiyyah, http://www. imam-khomeini.com/web1/arabic/showitem.aspx?cid=2004\&h=19\& $f=20 \&$ pid=2337 (2 Desember 2014).

, t.t. Al-Washiyyah al-Ilahiyyah al-Siyasiyyah, http://arabic.irib.ir/ Monasebat/E-khomeini/vasiyat2.htm (1 September 2016).

,Wasyiyyat al-Imam al-Khumaini, http://www.eslam.de/arab / manuskript_arab/testament/testament_imam_chomeini.htm (26 Desember 2016).

Khu'i, Sayyid al-. tt, I'jaz al-Quran, http://www.alkhoei.net/ar/Opinion/5/3- نآرقلاز زاجعا ميركسا dan http://al-khoei.us/edara/index.php?id=32 (21 Oktober 2015).

Katsir, Abu al-Fida' Ibn. 2004. Thabaqat asy-Syafi'iyyin, Dar al-Wafa ', alManshurah.

Mawardi, Abu al-Hasan Ali al- 1999. al-Hawi al-Kabir, tahqiq: Ali Muhammad Mu'awwidh dan Adil Ahmad, Beirut: Dar al-Kutub al-'Ilmiyyah.

Muthraji, Mahmud. t.t. Sirah Imam Muhamad ibn Idris asy-Syafi'i dalam kitab al-Umm, Beirut: Dar al-Kutub al-Ilmiyyah.

Manzhur, Jamaluddin Abu al-Fadhl Muhammad ibn. t.t. Lisan al-Arab, materi sanad, Dar al-Ma'arif.

Muhammadi, Muhammad. 2009. Kisah-Kisah Nahj al-Balaghah. Jakarta: PT. Trisula Adisakti.

Naisaburi, Muslim ibn Hajjaj al-. t.t. al-Musnad al-Shahih, tahqiq: Muhammad Fuad Abdul Baqi, Beirut: Dar Ihya`al-Turats al-'Arabi

Nasir, Malki Ahmad. 2012. Konsep ilmu dan Aplikasinya dalam Pembangunan (1).. http://insistnet.com./konsep-mu-dan-aplikasinya-dalam-pembangunan-1/ (19 Agustus 2015).

Nu'aim, Abu. 1974. Hilyah al-Auliya wa Thabaqah al-Ashfiya ', Mesir: al-Sa'adah.

Qari, Ali al-. t.t. Syarh 'Ali al-Qari 'Ala Syarh Nukhbah al-Fikr. Beirut: Dar alArqam.

Qifari, Nashir al-. 1414. Ushul Madzhab al-Syiah al-Imamiyyah al-Itsnay Asyariyyah. Jizah Saudi Arabia: Dar al-Ridha. 
Qummi, Shadiq Hasan Zadeh al-. t.t. Pesan Imam Khumaini, http://balaghah. net/old/nahj-htm/id/id/01/10.htm (9 September 2015).

Radhi, al-Syarif al-. 1406. Khashaish al-Aimmah, Masyhad Iran, Majma' alBuhuts al-Islamiyyah.

Rifa'i, Shalih al-. t.t. 'Inayah al-Ulama' bi al-Isnad wa 'Ilm al-Jarh wa al-Ta'dil wa Atsaru Dzalika fi Hifzh as-Sunnah al-Nabawiyyah,Madinah KSA: Majma al-Malik Fahd Lithibaah al-Mushhaf.

Sijistani, Abu Daud Sulaiman al-, t.t. Sunan Abi Daud, tahqiq: Muhamad Muhyiddin Abdul Hamid, Beirut: al-Maktabah al-'Ashriyyah.

Segaf, Alawi ibn Abd al-Qadir al. t.t. http://www.dorar.net/enc/firq/711, diakses, Kamis 1 September 2016.

Suyuthi, Jalaluddin al-, t.t. al-Khashaish al-Kubra, Beirut: Dar al-Kutub al-Ilmiyyah. , t.t. Shaun al-Manthiq wa al-Kalam 'an 'ilm al-Manthiq wa al-Kalam.

Shalah, Usman ibn Abdirrahman ibn al-. 1986. Ma'rifah Anwa' 'Ulum al-Hadits (Muqaddimah Ibn al-Shalah), tahqiq: Nuruddin 'itr, Beirut: Dar al-Fikr.

Subki, Tajuddin ibn Taqiyyuddin al- 1413. Thabaqat al-Syafi'iyyah al-Kubra, tahqiq: Mahmud Muhammad al-Thanahi dan Abdul Fattah Muhammad al-Huluw, Hajar.

Syafi' i, Muhammad Ibn Idris, 2010, Diwan al-Imam Al-Syafi'i, Beirut: Dar alKutub al-Ilmiyah.

Syaharastani, Abu al-Fath Al-(548 H). al-Milal wa al-Nihal, Muassasah al-Halabi.

Taimiyyah, Syaikh al-Islam Ibn. 1999. al-Jawab al-Shahih Liman Baddala Dinal Masih, tahqiq: Ali ibn Hasan dkk, Saudi: Dar al-'Ashimah.

Turmudzi, Abu Isa Muhammad al-, 1975, Sunan Turmudzi, Mesir, Maktabah Mushthafa al-Babi al-Halabi.

Zahra, Abd al-, 1405. Mashadir Nahj al-Balaghah wa Asaniduhu, Beirut: Dar al-Adhwa .

Zamakhsyari, Abu al-Qasim Mahmud al-. t.t. Asas al-Lughah, Kairo: Dar Mathabi' al-Sya'b.

el Harakah Jurnal Budaya Islam Vol.18 No.2 Tahun 2016 
el Harakah Jurnal Budaya Islam Vol.18 No.2 Tahun 2016 